\title{
Variación del peso durante el primer mes de vida en recién nacidos de término sanos con lactancia materna exclusiva
}

\author{
MARÍA COVAS ${ }^{1}$, ERNESTO ALDA ${ }^{1}$, SILVIA VENTURA ${ }^{1}$, \\ SILVIA BRAUNSTEIN² ${ }^{2}$, GABRIELA SERRALUNGA ${ }^{3}$, LORETO YÁÑEZ ${ }^{3}$ \\ 1. Servicio de Neonatología. Hospital Privado del Sur. Bahía Blanca. \\ 2. Ciencias de la Computación. UBA. \\ 3. Área de Probabilidad y Estadística. Departamento de Matemáticas. Universidad Nacional del Sur. Bahía Blanca.
}

\section{RESUMEN}

La variación del peso en recién nacidos sanos resulta de interés clínico, principalmente en aquellos niños con lactancia materna exclusiva. Objetivos: Determinar el cambio relativo del peso al nacer durante el primer mes, en recién nacidos de término sanos, alimentados exclusivamente con pecho. Diseño. Observacional; tipo cohorte. Prospectivo. Población, Material y Métodos: Recién nacidos asistidos entre septiembre de 2000 y noviembre de 2001. Criterios de elegibilidad: recién nacidos de término sanos $(\geq 37$ semanas de gestación). No elegibles: gemelares o con internación en la primera semana de vida (exceptuando ictericia y deshidratación hipertónica). Criterios de inclusión: pecho exclusivo al mes de vida; mínimo 4 controles de peso. Criterios de eliminación: niños que completaron los controles pero en días diferentes a los preestablecidos. Resultados: Recién nacidos: 1 669; fueron elegibles al momento del nacimiento: 1479 ; cumplieron los criterios de inclusión: 810. El descenso máximo de peso se registró al $3^{\text {er }}$ día (promedio -8\%), la media de recuperación del peso de nacimiento fue al $8^{\circ}$ día y el promedio de incremento al mes fue de $+30 \%$. Al considerar la edad gestacional $(<39-39$ y $>39$ semanas) y el peso al nacimiento $(<3000 ; 3000-$ $3500 ;>3500 \mathrm{~g}$ ), no se hallaron diferencias significativas; no obstante, los más pequeños al nacer presentaron una mayor variación del peso al mes. Las dificultades en la alimentación se asociaron con mayor internación por ictericia y deshidratación, junto a una recuperación más tardía del peso de nacimiento $\left(13^{\text {er }}\right.$ día). Los nacidos por parto vaginal presentaron un incremento de peso superior. Conclusiones: El conocimiento de los cambios relativos del peso al nacimiento permitió graficar sus variaciones y evaluar las diferencias existentes entre grupos con distintas características perinatales. Esta información podría ser de utilidad para ratificar conductas, principalmente en el fomento y difusión de la lactancia materna exclusiva en poblaciones similares a la de la presente investigación.

(Palabras clave: Lactancia materna; Crecimiento; Recién nacido). Arch Argent Pediatr 2006; 104 (5): 399-405

ESTE TRABAJO LO PUEDE ENCONTRAR EN EXTENSO EN WWW.SCIELO.CL

Correspondencia a:

Ernesto Alda

E-mail: eralda@criba.edu.ar 